\title{
Experimental Study on Concrete Columns Confined with External FRP
}

\author{
Ana de Diego ${ }^{1}$, Sonia Martínez ${ }^{1}$, José Pedro Gutiérrez ${ }^{1}$, Luis Echevarría1 \\ ${ }^{1}$ IETCC, CSIC. Eduardo Torroja Institute for Construction Science \\ C/ Serrano Galvache nº 4, 28033, Madrid, Spain \\ adediego@ietcc.csic.es; soniamdm@ietcc.csic.es; jpgutierrez@ietcc.csic.es; 1.echevarria@ietcc.csic.es
}

\begin{abstract}
It is known that confinement with FRP (fibre reinforced polymer) jackets is a useful reinforcement technique to improve the strength and ductility of concrete columns subjected to axial compression loads, especially in those that have a circular cross section. This strengthening method is less effective for elements with square or rectangular sections in which, unlike the circular ones, the FRP confinement is not uniform. However, concrete columns with non-circular cross section are very common in construction, so it is essential to be able to estimate adequately the ultimate capacity of the reinforced element depending on the shape of the section. Most of the international guidelines for the design and calculation of this type of reinforcements recognize this circumstance and incorporate a shape factor, although there is no unanimity in their proposals. This paper presents the preliminary results of an experimental study on intermediate-sized concrete specimens reinforced with FRP jackets. Special attention is paid to two parameters related to the section shape that have an important impact on the efficiency of the reinforcement on rectangular sections: the aspect ratio of the cross section or relationship between the sides of the concrete section $(b / d)$ and the radius of curvature of the corners $\left(R_{c}\right)$. This work is part of a research project that includes a larger experimental program with full-scale tests.
\end{abstract}

Keywords: Confinement, Fibre-reinforced polymer (FRP), RC column, Experimental program.

\section{Introduction}

Concrete confinement by transverse reinforcement can improve the strength and ductility of axially loaded members. Numerous experimental studies have been carried out on the behaviour of FRP-confined concrete [1-2] and theoretical models have been proposed [3-4]. Most of the experimental studies have focused on circular-section specimens and several empirical models have been formulated. It is widely accepted that the confinement of non-circular columns is less efficient than the confinement of circular columns as it has been shown by several studies [5-6]. In a circular cross section, the jacket exerts a uniform confining pressure over the entire perimeter. In the case of a rectangular cross section, the confining action is mostly concentrated at the corners. In the theoretical analysis of rectangular sections, models found in current design guides [7-9] are usually based on ones created for circular columns and then modified by a shape factor to take into account the effect of the section form.

This paper presents the preliminary results of an experimental study on rectangular concrete specimens strengthened with FRP jackets. The variables studied include the aspect ratio of the cross section $(b / d)$ and the radius of curvature of the corners $\left(R_{c}\right)$, in order to study the influence of the column shape on the confinement effectiveness.

\section{Experimental program and main parameters}

The study described in this communication is part of the Research Project BIA2016-80310-P, "Study of reinforcement of rectangular reinforced concrete pillars with FRP based on real-scale tests and proposal of a new calculation model" financed by AECI and FEDER. The general objective of this Project is to carry out a theoretical and experimental investigation to propose a calculation model to obtain the stress-strain response, the resistance and the ultimate strain of reinforced concrete columns of circular, square and rectangular section, confined with composite materials (FRP). In order to validate the model experimentally, the project includes an own experimental program with two phases: 1) tests of intermediate size specimens with square and rectangular sections and 2) real scale prototypes with circular, square and rectangular sections. In the present work, results of the first phase are presented.

Axial compression tests have been performed on 25 plain concrete prismatic specimens with square and rectangular section. 24 of them have been externally strengthened with CFRP (carbon FRP) and one specimen has been tested without 
reinforcement as a reference. The specimens were instrumented with strain gauges to measure the axial and transversal strain in the central zone on all four faces.

The tests presented in this paper are part of a more extensive experimental program whose variables are:

- The aspect ratio of the cross section $(b / d)$ : square section $(b / d=1)$ and rectangular with $b / d=1.5$ and $b / d=2$.

- The radius of curvature of the corners $\left(R_{c}\right): 20,25$ and $30 \mathrm{~mm}$.

- The amount of FRP reinforcement, the specimens have been strengthened with different number of FRP layers.

Thereafter the specimens were named as follows: first the cross section aspect ratio $(b / d)$ is indicated, followed by the radius of curvature of the corners $\mathrm{Rc}$ in $\mathrm{mm}$ and finally the number of layers of the FRP strengthening. In those cases in which specimens with the same characteristics are tested, the letter $\mathrm{a}$ or $\mathrm{b}$ is placed at the end.

Concrete prismatic specimens were formed with a length of $600 \mathrm{~mm}$ and three different types of section: square section $\left(150 \times 150 \mathrm{~mm}^{2}\right)$ and rectangular section with aspect ratio $b / d=1.5\left(150 \times 225 \mathrm{~mm}^{2}\right)$ and $b / d=2\left(150 \times 300 \mathrm{~mm}^{2}\right)$. The value of the concrete compressive strength $\left(f_{c o}\right)$ was obtained by testing cylindrical normalized specimens.

Specimens were strengthened by wrapping with unidirectional carbon fibre sheets and epoxy resin. Fibres are oriented in a direction perpendicular to the axis of the pillar with a minimum overlap length of $100 \mathrm{~mm}$. The net fibre thickness is $0.129 \mathrm{~mm}$ for each layer. Tensile testing of FRP flat coupons has been carried out. It was obtained a mean value of tensile strength of $4161 \mathrm{~N} / \mathrm{mm}^{2}$ and a modulus of elasticity equal to $236918 \mathrm{~N} / \mathrm{mm}^{2}$ (both referred to the net section of fibre). The specimens were reinforced along their full length with 1,2 or 3 layers of fibre, according to the test plan. Only for rectangular specimens with a shape factor $(b / d)$ equal to 2, 4 layers of CFRP were used.

\section{Experimental results}

Table 1: Experimental results.

\begin{tabular}{|c|c|c|c|c|c|c|}
\hline & & Specimen & $\mathrm{f}_{\mathrm{co}}[\mathrm{MPa}]$ & $\mathbf{Q}_{\max }[\mathrm{kN}]$ & $\mathbf{f}_{\text {cc }}[\mathrm{MPa}]$ & $\mathbf{f}_{\mathrm{cc}} / \mathbf{f}_{\mathrm{co}}$ \\
\hline \multicolumn{2}{|l|}{$\mathrm{b} / \mathrm{d}=1$} & Reference a & 35.3 & 730.9 & 33.0 & 0.93 \\
\hline \multirow[t]{7}{*}{$\mathrm{b} / \mathrm{d}=1$} & \multirow[t]{3}{*}{$\mathrm{f}_{\mathrm{co}} \cong 25 \mathrm{MPa}$} & 1_20_2b & 25.1 & 1102.1 & 49.7 & 1.98 \\
\hline & & 1_25_2a & 25.1 & 1209.3 & 55.1 & 2.19 \\
\hline & & $1 \_25 \_2 b$ & 25.1 & 1209.9 & 55.1 & 2.19 \\
\hline & \multirow[t]{4}{*}{$\mathrm{f}_{\mathrm{co}} \cong 35 \mathrm{MPa}$} & 1_20_1a & 35.3 & 803.6 & 36.3 & 1.03 \\
\hline & & 1_20_2a & 35.3 & 1071.7 & 48.4 & 1.37 \\
\hline & & 1_25_3a & 34.4 & 1593.6 & 72.6 & 2.11 \\
\hline & & 1_30_3a & 34.4 & 1731.1 & 79.7 & 2.32 \\
\hline \multirow[t]{11}{*}{$\mathrm{b} / \mathrm{d}=1.5$} & \multirow[t]{3}{*}{$\mathrm{f}_{\mathrm{co}} \cong 21 \mathrm{MPa}$} & $1.5 \_20 \_2 b$ & 20.6 & 1238.6 & 37.1 & 1.80 \\
\hline & & $1.5 \_25 \_2 \mathrm{a}$ & 20.6 & 1242.9 & 37.4 & 1.81 \\
\hline & & $1.5 \_30 \_2 b$ & 20.6 & 1154.7 & 35.0 & 1.70 \\
\hline & \multirow[t]{3}{*}{$\mathrm{f}_{\mathrm{co}} \cong 27 \mathrm{MPa}$} & 1.5_20_2 & 27.1 & 1307.1 & 39.1 & 1.44 \\
\hline & & $1.5 \_25 \_2 b$ & 27.1 & 1256.7 & 37.8 & 1.40 \\
\hline & & 1.5_30_2c & 27.1 & 1442.7 & 43.8 & 1.61 \\
\hline & \multirow[t]{5}{*}{$\mathrm{f}_{\mathrm{co}} \cong 35 \mathrm{MPa}$} & 1.5_20_2a & 35.3 & 1212.6 & 36.3 & 1.03 \\
\hline & & 1.5_30_2a & 35.3 & 1221.0 & 37.0 & 1.05 \\
\hline & & $1.5 \_20 \_3 \mathrm{a}$ & 34.4 & 1497.5 & 44.8 & 1.30 \\
\hline & & $1.5 \_25 \_3 \mathrm{a}$ & 34.4 & 1640.1 & 49.4 & 1.44 \\
\hline & & 1.5_30_3a & 34.4 & 1726.6 & 52.4 & 1.52 \\
\hline \multirow[t]{6}{*}{$\mathrm{b} / \mathrm{d}=2.0$} & \multirow[t]{3}{*}{$\mathrm{f}_{\mathrm{co}} \cong 23 \mathrm{MPa}$} & 2_20_3a & 22.8 & 1138.1 & 25.5 & 1.12 \\
\hline & & 2_25_3a & 22.8 & 1202.5 & 27.0 & 1.19 \\
\hline & & 2_30_3b & 22.8 & 1266.9 & 28.6 & 1.26 \\
\hline & \multirow[t]{3}{*}{$\mathrm{f}_{\mathrm{co}} \cong 30 \mathrm{MPa}$} & $2 \_30 \_3 a$ & 29.8 & 1533.7 & 34.7 & 1.16 \\
\hline & & 2_20_4a & 29.8 & 1745.3 & 39.1 & 1.31 \\
\hline & & 2_25_4a & 29.8 & 1803.8 & 40.6 & 1.36 \\
\hline
\end{tabular}

Experimental results are summarized in Table 1, indicating for each test: the unconfined concrete strength $\left(f_{c o}\right)$; the ultimate axial load $\left(Q_{\max }\right)$; the confined concrete strength $\left(f_{c c}\right)$ and the strength enhancement ratio $\left(f_{c c} f_{c o}\right)$. The unconfined 
concrete strength $\left(f_{c o}\right)$ is a determining parameter in the degree of improvement obtained thanks to the FRP strengthening. For this reason the results collected in Table 1 are grouped for specimens with the same shape factor (b/d equal to $1,1.5$ and 2) and similar unconfined concrete strength (between $21 \mathrm{MPa}$ and $35 \mathrm{MPa}$ ).

\section{Analysis of experimental results}

For the square specimens with an unconfined concrete strength $\left(f_{c o}\right)$ equal to $25 \mathrm{MPa}$, the concrete strength is doubled by applying two CFRP layers. For specimens with a higher unconfined concrete strength (around $35 \mathrm{MPa}$ ), one CFRP layer practically didn't improve the concrete strength. However, with two and three layers there is a remarkable enhancement (37\% and $110 \%$ respectively), the results are better when the corner radius is greater.

The stress-strain response of square specimens with $f_{c o}$ around $35 \mathrm{MPa}$ and two and three CFRP layers (Figure 1a) is approximately bilinear, which second branch is upward, meaning a sufficient FRP confinement. However, for the strengthened specimen with only one CFRP layer, the second branch isn't upward although the confined concrete strength is lightly higher than the reference test.

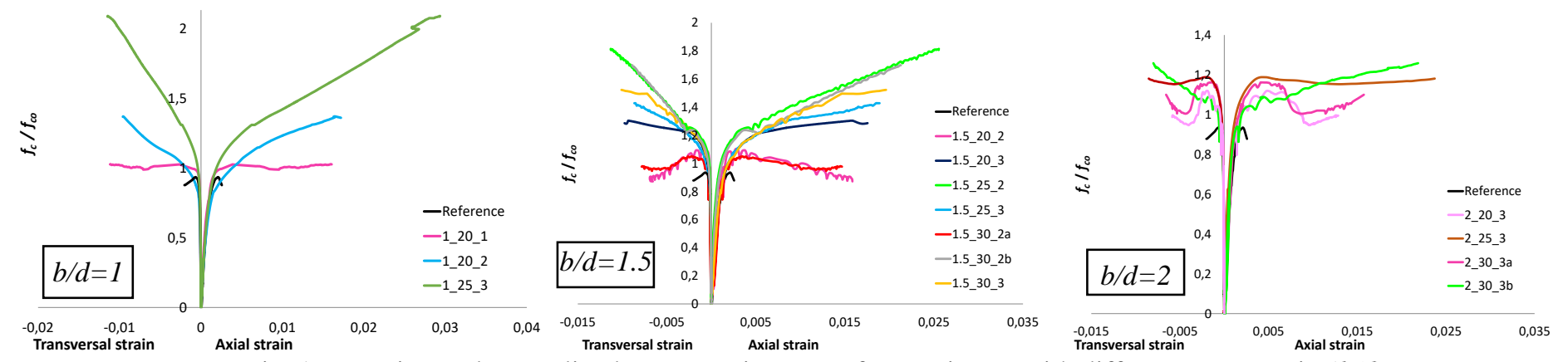

Fig. 1: Experimental normalized stress-strain curves for specimens with different aspect ratio $(b / d)$.

The rectangular specimens with an aspect ratio $(b / d)$ equal to 1.5 were manufactured with three different values of strength concrete $\left(f_{c o}\right): 21 \mathrm{MPa}, 27 \mathrm{MPa}$ and $35 \mathrm{MPa}$, approximately. For specimens with $f_{c o}$ around $21 \mathrm{MPa}$ strengthened with two CFRP layers, strength enhancement ratios $\left(f_{c c} d f_{c o}\right)$ between $70 \%$ and $80 \%$ are obtained, and the typical bilinear behaviour with an ascendant second branch can be observed. For specimens with a medium concrete strength (27 MPa) and two reinforcement layers the improvement are between $40 \%$ and $61 \%$, being more favourable for the larger corner radius. For specimens with $f_{c o}=35 \mathrm{MPa}$ the reinforcement with two layers is not enough to improve the concrete strength (in Figure 1b it is observed that the corresponding stress-strain curves have a descending branch), while with three layers increases between 30 and $50 \%$ are obtained.

For rectangular specimens with $b / d=2.0$ the effectiveness of the confinement is clearly lower, especially, for specimens with higher concrete strength. For specimens with $f_{c o}=23 \mathrm{MPa}$, it was necessary to apply 3 layers of CFRP in the sample with the larger radius of curvature of the corners $(30 \mathrm{~mm})$ to obtain an improvement of $26 \%$. For a higher concrete strength (35 MPa) the strength improvement achieved with three layers is around $16 \%$, being necessary to apply 4 CFRP layers to obtain increments of $36 \%$. It is observed an ascending bilinear behaviour in the specimen 2_30_3b, strengthened with three layers and with an unconfined concrete strength around of $23 \mathrm{MPa}$ (Figure 1c).

It should be noted that in all cases the ultimate concrete axial strain increases remarkably.

Although the number of test pieces tested so far is small, the tests carried out show that the efficiency of the FRP confinement is higher when the radius of curvature of the corners is greater. 

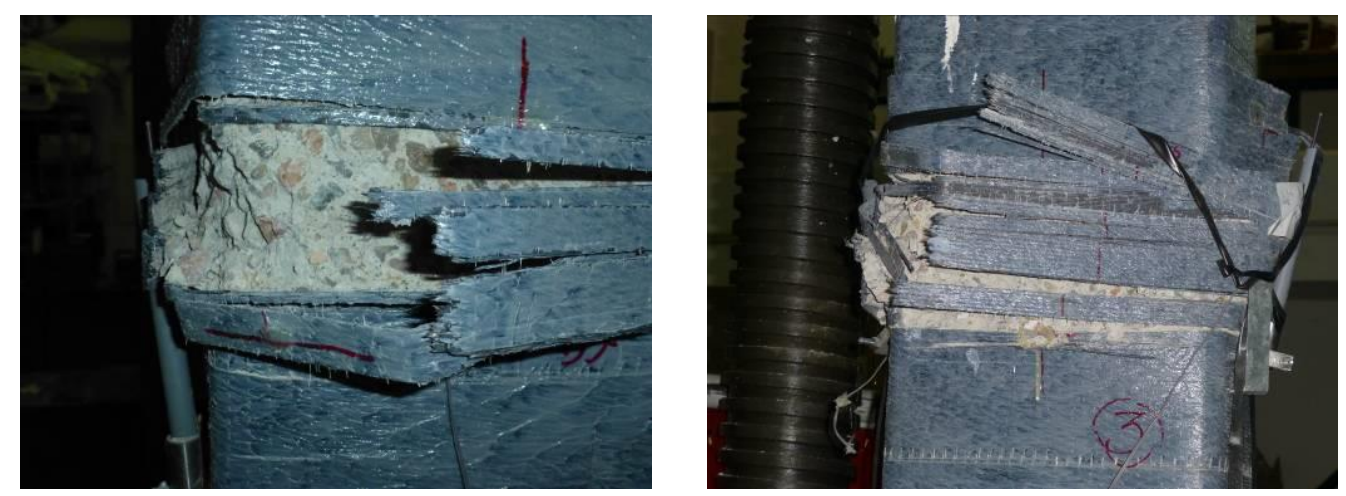

Fig. 2: Failure of specimens.

The failure usually occurs suddenly by tensile rupture of the FRP near a corner (Figure 2). The strains measured on the fibres at the time of rupture $\left(\varepsilon_{f, e f f}\right)$ were significantly lower than the ultimate strains obtained by tensile testing of flat coupons $\left(\varepsilon_{f}\right)$. The average value of the ratio $\varepsilon_{f, e f f} / \varepsilon_{f}$, is near to 0.5 . It is similar to the proposed one in existing guides.

\section{Conclusions}

The main conclusions of the detailed experimental program are:

- Confinement with FRP composites can significantly improve the bearing capacity and ductility of square section reinforced concrete columns with rounded corners. The strength enhancement ratio is greater the lower the concrete strength and also increases with the amount of FRP confinement.

- In rectangular sections with an aspect ratio $(b / d)$ equal to 1.5 , the efficiency of the strengthening is smaller, being necessary to increase the amount of reinforcement. In the specimens with an aspect ratio $(b / d)$ equal to 2, it wasn't obtained enough strengthening if the unconfined concrete strength was about $35 \mathrm{MPa}$, but it achieved for specimens which unconfined concrete strength was around 21 and $27 \mathrm{MPa}$. More tests are needed to draw conclusions in this regard.

- The strength enhancement ratio $\left(f_{\mathrm{c}} / f_{\mathrm{co}}\right)$ increases with the amount of FRP and, for a given amount, with the corner radius $(R c)$. The stress-strain response is approximately bilinear with a smooth transition zone. In the first region, the behaviour is similar to that of unconfined concrete. With rounded corners and sufficient confinement ratio the second branch of the curve is also monotone upward, being more ascending for the bigger amount of FRP strengthening and, for the same FRP amount, increasing for greater radius of the corners. For inadequate confinement ratio, the second branch is almost horizontal or, even, descending.

- The failure usually occurs suddenly and explosively by tensile rupture of the jacket fibres to a strain value much lower than that obtained by tensile testing of FRP coupons.

The above conclusions should be considered within the scope of the studied parameters, and with the limitations derived from the small number of tests carried out so far. The presented work is part of a more extensive experimental program, in which the specimens on a real scale will be also tested in order to confirm these conclusions.

\section{Acknowledgements}

This work is part of the Project BIA2016-80310-P, funded by AECI and FEDER, and the Project PIE-201460E049 funded by the Spanish National Research Council. FRP materials were supplied by SIKA, SAU.

\section{References}

[1] Y. Xiao and H. Wu, "Compressive behavior of concrete confined by various types of FRP composite jackets," J. Reinf Plast. Compos., vol. 22, no. 13, pp. 1187-1201, 2003.

[2] T. M. Pham, M. N. S. Hadi and J. Youssef, "Optimized FRP wrapping schemes for circular concrete columns under axial compression," J. Compos. Constr., vol. 19, no. 6, 2015.

[3] J. G. Teng, T. Jiang, L. Lam and Y. Z. Luo, "Refinement of a design-oriented stress-strain model for FRP-confined concrete," J. Compos. Constr., vol. 13, pp. 269-278, 2009.

[4] R. Realfonzo and A. Napoli, "Concrete confined by FRP systems: confinement efficiency and design strength 
models," Compos. B. Eng., vol. 42, pp. 736-755, 2011.

[5] O. Chaallal, M. Shahawy and M. Hassan, "Performance of axially loaded short rectangular columns strengthened with carbon fiber-reinforced polymer wrapping," J. Compos. Constr., vol. 7, no. 3, pp. 200-208, 2003.

[6] A. de Diego, A. Arteaga, J. Fernández, R. Perera and D. Cisneros, "Behaviour of FRP confined concrete in square columns," Mater. Construc., vol. 65, no. 320, 2015.

[7] Concrete Society, TR55. Technical Report Design guidance for strengthening concrete structures using fibre composite materials. 3rd ed., UK, 2012.

[8] National Research Council, Advisory Committee on Technical Recommendations for Construction, CNR-DT200_R1. Guide for the Design and Construction of Externally Bonded FRP Systems for Strengthening Existing Structures. Italy, 2013.

[9] American Concrete Institute, ACI-440.2R-08. Guide for the design and construction of externally bonded FRP systems for strengthening concrete structures. Farmington Hills, Michigan, 2008. 